\title{
Increased circulating soluble urokinase-type plasminogen activator receptor (suPAR) levels in patients with slow coronary flow
}

\author{
Acar Emrah ${ }^{1}$, İgi İbrahim Akın ${ }^{1}$, İzi Servet ${ }^{1}$, Kahyaoğlu Muzaffer ${ }^{1}$, Yılmaz Mehmet Fatih ${ }^{1}$, \\ Güler Yeliz${ }^{1}$, Efe Süleyman Çağan², Güler Ahmet ${ }^{1}$, Kılıçgedik Alev ${ }^{1}$, Kırma Cevat ${ }^{1}$
}

\author{
${ }^{1}$ Department of Cardiology, Kartal Kosuyolu Cardiovascular Research and Training \\ Hospital, Istanbul, Turkey \\ ${ }^{2}$ Clinic of Cardiology, Ağrı State Hospital, Agri, Turkey
}

Submitted: 23 May 2016

Accepted: 15 June 2016

Arch Med Sci Artheroslcer Dis 2016; 1: e53-e59

DOI: 10.5114/amsad.2016.60819

Copyright @ 2016 Termedia \& Banach

\begin{abstract}
Introduction: Slow coronary flow (SCF) is an angiographic phenomenon characterized by delayed opacification of epicardial coronary arteries without an obstructive coronary disease. Serum soluble urokinase-type plasminogen activator receptor (sUPAR) levels seem closely related to atherosclerosis due to increased inflammation and prothrombotic state. We studied whether circulating suPAR is related to SCF.

Material and methods: The present study was cross-sectional and observational. It included 75 individuals who underwent coronary angiography with suspected CAD and had angiographically normal coronary arteries of varying coronary flow rates. The relationship between suPAR, C-reactive protein (CRP) and SCF was investigated. Forty patients with isolated SCF (mean age: $46.0 \pm 4.14$ years) and 35 age- and gender-matched control participants with normal coronary flow (NCF) and normal coronary arteries (NCA) (mean age: $46.0 \pm 5.7$ years) were included in the study. We used logistic regression analysis to determine the predictors of SCF.

Results: The clinical characteristics were not statistically significantly different between SCF and NCA groups. Serum suPAR level was significantly higher in the SCF group than the control group $(2.5-5.4 \mathrm{ng} / \mathrm{ml}$ vs. 0.1-1.4 ng/ $\mathrm{ml} ; p<0.001)$. Also the serum CRP level was higher in the CSF group than the control group $(1.57 \pm 0.43 \mathrm{mg} / \mathrm{l} \mathrm{vs} .0 .53 \pm 0.23 \mathrm{mg} / \mathrm{l} ; p<0.001)$.

Conclusions: This study revealed significantly increased serum suPAR levels in patients with SCF. Although we cannot draw conclusions on the underlying pathological process of SCF, we believe that these findings may be pioneering for further studies investigating the specific roles of circulating SUPAR in the SCF phenomenon in the coronary vasculature.
\end{abstract}

Key words: coronary slow flow, sUPAR, high-sensitivity C-reactive protein, coronary angiography, regression analysis.

\section{Introduction}

Slow coronary flow (SCF) is a common angiographic finding characterized by delayed opacification of epicardial coronary arteries without obstructive coronary disease $[1,2]$. It is reported that the incidence of SCF is $1 \%$ in patients undergoing coronary angiography for suspected coronary artery disease (CAD) [2]. Since the first description in 1972 by Tambe

\author{
Corresponding author: \\ Acar Emrah \\ Department of Cardiology \\ Kartal Kosuyolu \\ Cardiovascular Research \\ and Training Hospital \\ 34786 Istanbul, Turkey \\ Phone: +905358819708 \\ E-mail: dreacar44@hotmail. \\ com
}


et al. [1], there have been many reports with the aim of describing the precise pathophysiological mechanisms such as small vessel disease, microvascular vasomotor dysfunction, diffuse atherosclerosis, and endothelial dysfunction [3-6]. Occlusive disease of the small coronary arteries, which may be a form of early-phase atherosclerosis, has also been suggested as a cause [7]. Also, it is reported that SCF may cause transient myocardial hypoperfusion in patients with angina and normal coronary arteries, and these patients have a higher chance of significant coronary artery disease and an apparently worse prognosis [8].

sUPAR is a novel proinflammatory biomarker and chemotactic agent [9] that is released by cleavage of the membrane-bound urokinase type plasminogen activator receptor (UPAR). SUPAR is ubiquitous in body fluids including the plasma, urine, and cerebrospinal fluid, is involved in the inflammatory processes and promotes the body's immune response. Up-regulation of UPAR is manifested by raised blood suPAR levels and has been observed in many conditions such as rheumatologic conditions, malignancies, infections, sepsis and cardiovascular diseases [10-20]. suPAR is also thought to be involved in atherosclerotic processes such as endothelial dysfunction, macrophage-mediated inflammation and immune dysregulation [21]. The physiological role and pathophysiological importance of sUPAR in SCF are unclear. Since SCF seems to be an early form of atherosclerosis and low-grade inflammation plays a major role in the atherosclerotic vascular processes, suPAR-related inflammation may also be involved in SCF as well.

The aim of this study was to investigate whether suPAR level and high-sensitivity C-reactive protein (hs-CRP) levels are higher in patients with SCF compared to patients with angiographically normal coronary arteries. We also evaluated the potential relationship between these markers and Thrombolysis in Myocardial Infarction (TIMI) frame count.

\section{Material and methods}

\section{Study design and patient population}

The present study was cross-sectional and observational. We randomly selected a total of 75 individuals from patients who underwent coronary angiography with suspicion of CAD, between March 2015 and October 2015, at our institute's outpatient clinic, and had angiographically normal coronary arteries (NCA) of varying coronary flow rates without any atherosclerotic lesions. They were enrolled in the study. All patients had chest pain or angina equivalent symptoms with either positive treadmill test or myocardial perfusion study. Clinical characteristics, which consisted of multiple descriptors from each patient's history and physical examination, were collected by physicians from the cardiology clinic of each patient at the time of cardiac catheterization and were stored in the database of coronary angiography laboratory at our institution. Patients with known coronary or peripheral vascular disease, ectatic coronary arteries, non-ischemic dilated cardiomyopathy, renal and hepatic dysfunction, evidence of ongoing infection or inflammation, hematological disorders, and known malignancy were excluded from the study. None of the participants in the study was on any vasoactive drugs.

The study was performed in accordance with the principles stated in the Declaration of Helsin$\mathrm{ki}$ and approved by the local Ethics Committee of Marmara University, Faculty of Medicine. Informed consent was obtained from all patients prior to the study.

\section{Biochemical measurements}

Blood samples were drawn by venipuncture to measure routine blood chemistry parameters after fasting for at least $8 \mathrm{~h}$. Fasting blood glucose, serum creatinine, total cholesterol, high-density lipoprotein cholesterol, low-density lipoprotein cholesterol, and triglyceride levels were recorded. Glucose, creatinine, and lipid profile were determined by standard methods. Serum CRP was analyzed using a nephelometric technique (Beckman Coulter Immage 800; Fullerton, CA, USA; normal range $0-0.8 \mathrm{mg} / \mathrm{dl}$ ). Blood samples for suPAR were drawn after coronary angiography and serum, isolated by centrifugation within $1 \mathrm{~h}$ at $2500 \mathrm{~g}$ for $10 \mathrm{~min}$, and stored at $-80^{\circ} \mathrm{C}$. Serum levels of suPAR were measured using commercially available kits according to the manufacturer's instructions (suPARnostic kit; ViroGates, Copenhagen, Denmark) Minimum detectable high-sensitivity C-reactive protein (hs-CRP) and suPAR were $0.1 \mathrm{mg} / \mathrm{l}$ and $0.1 \mathrm{ng} / \mathrm{ml}$, respectively.

\section{Coronary angiography and determination of SCF}

Coronary angiography was performed by the femoral approach using the standard Judkins technique. Coronary angiograms were recorded in right and left oblique planes using cranial and caudal angulations, with a rate of 30 frames/s. During coronary angiography, iopromide (Ultravist 370, Schering AG, Berlin, Germany) was used as the contrast agent in all patients and control participants.

TIMI frame count was derived from the number of cine-frames recorded from the first entrance of contrast to its arrival at the distal end of the left anterior descending artery (LAD), the circumflex artery (CX), or the right coronary artery (RCA) [22]. It is a quantitative, simple, objective and re- 
producible index of coronary flow velocity [22]. The initial frame count is defined as the frame in which concentrated dye occupies the full width of the proximal coronary artery lumen, touching both borders of the lumen, and exhibiting forward motion down the artery. The final frame is designated when the leading edge of the contrast column initially arrives at the distal end. The last frames used for the LAD, Cx and RCA were those in which the dye first entered the mustache segment, distal bifurcation segment, and first branch of the posterolateral artery, respectively. The final count was then subtracted from the initial count and the exact TIMI frame count was calculated for the given artery. The TIMI frame count of the LAD artery was corrected by dividing the final count by 1.7. The mean TIMI frame count for each patient and control subject was calculated by adding the TIMI frame counts for LAD, CX and RCA and then dividing the obtained value into three. Coronary angiograms and TIMI frame counting were analyzed by two blinded interventional cardiologists without knowledge of the clinical status and laboratory measurements of the subjects. Due to different durations required for normal visualization of coronary arteries, the corrected cutoff values were $36.2 \pm 2.6$ frames for LAD, $22.2 \pm 4.1$ frames for Cx, and $20.4 \pm 3.0$ frames for RCA, as has been reported earlier in the literature [22]. Any values in excess of these thresholds were considered as SCF.

\section{Statistical analysis}

Data were analyzed with the SPSS software version 10.0 for Windows (SPSS Inc., Chicago, IL, USA). Continuous variables from the study groups were reported as mean \pm standard deviation, categorical variables as percentages. To compare continuous variables, Student's $t$-test or the Mann-Whitney $U$ test was used where appropriate. Categorical variables were compared with the chi-square test. The correlations between serum suPAR, hs-CRP levels, and mean TIMI frame count were performed with Pearson correlation analysis. The relationship between serum suPAR levels and mean TIMI frame count and serum hs-CRP levels and mean TIMI frame count were tested in a linear regression model adjusted for confounding factors such as age, gender, body mass index (BMI), smoking, glucose and cholesterol levels. Standardized beta coefficients and 95\% confidence intervals $(\mathrm{Cl})$ were calculated. Statistical significance was defined as $p<0.05$.

\section{Results}

\section{Clinical characteristics}

Clinical and laboratory characteristics of the patients with SCF and the control group are pre- sented in Table I. There were no statistically significant differences between the two groups with respect to age, gender, body mass index, smoking, systolic and diastolic blood pressures, heart rate, ejection fraction and levels of glucose, creatinine, total cholesterol, triglyceride, low-density lipoprotein (LDL) cholesterol, high-density lipoprotein (HDL) cholesterol, or white blood cells. The TIMI frame count for all the epicardial coronary arteries and the mean TIMI frame count were significantly higher in the SCF group than the control group.

\section{Serum suPAR levels and hs-CRP levels in SCF}

Serum SUPAR levels were significantly higher among patients with SCF than controls $(3.71 \mathrm{ng}$ / $\mathrm{ml} ; 2.5-5.4 \mathrm{ng} / \mathrm{ml}$ vs. $0.75 \mathrm{ng} / \mathrm{ml} ; 0.1-1.4 \mathrm{ng} / \mathrm{ml}$ respectively; $p<0.001)$. Serum hs-CRP levels were significantly higher among patients with SCF than controls (1.57 \pm 0.43 vs. $0.53 \pm 0.23 \mathrm{mg} / \mathrm{l}$ respectively; $p<0.001)$.

\section{Relationship between serum suPAR levels and TIMI frame count}

In linear regression analysis, when suPAR levels were taken as the dependent variable with other study variables which are potential confounders such as age, gender, BMI, smoking, glucose and cholesterol levels, serum suPAR levels were only independently correlated with mean TIMI frame count $(\beta=0.60,95 \% \mathrm{Cl}$ : 4.23-8.56, $p<0.001$ ) (Figure $1 \mathrm{~A})$. When serum hs-CRP levels were taken as the dependent variable with other study variables which are potential confounders such as age, gender, BMI, smoking, glucose and cholesterol levels, serum hs-CRP levels were only independently correlated with mean TIMI frame count $(\beta=0.29$, 95\% Cl: 0.68-3.78, $p=0.003$ ) (Figure $1 \mathrm{~B}$ ).

\section{Discussion}

In this study, we found that suPAR and hs-CRP levels were significantly higher in patients with SCF than in control subjects. We also found a significant association of sUPAR and hs-CRP levels with TIMI frame count. Several mechanisms have been proposed for the etiology of SCF, including occlusion of small vessels, increased microvascular resistance, and diffuse atherosclerosis [1, 4, $5,7]$. However, the exact underlying pathophysiological mechanisms, as well as the clinical importance of this angiographic phenomenon, are not fully understood at present. Inflammation has been reported to be a major contributing factor to many cardiovascular events, and demonstrated to be associated with different clinical settings of coronary artery disease [21, 23].

Recently, inflammation has been suggested to play a role in the pathogenesis of SCF. Li et al. 
Table I. Clinical and laboratory characteristics of patients with CSF and control group

\begin{tabular}{|c|c|c|c|}
\hline Variables & $\begin{array}{l}\text { CSF group } \\
(n=40)\end{array}$ & $\begin{array}{l}\text { Control group } \\
\quad(n=35)\end{array}$ & $P$-value \\
\hline Age [years] & $46.0 \pm 4.14$ & $46 \pm 5.7$ & 0.98 \\
\hline Male gender (\%) & $25(62.5)$ & $23(65.7)$ & 0.772 \\
\hline Current smoking (\%) & $29(72.5)$ & $25(71.5)$ & 0.918 \\
\hline Family history of CAD (\%) & $7(17.5)$ & $7(20)$ & 0.782 \\
\hline \multicolumn{4}{|l|}{ Baseline hemodynamic data: } \\
\hline $\mathrm{SBP}[\mathrm{mm} \mathrm{Hg}]$ & $127.4 \pm 12.2$ & $125.2 \pm 11.2$ & 0.423 \\
\hline $\mathrm{DBP}[\mathrm{mm} \mathrm{Hg}]$ & $71.1 \pm 8.3$ & $67.1 \pm 9.2$ & 0.0540 \\
\hline Heart rate $[\mathrm{bpm}]$ & $80 \pm 6.5$ & $81 \pm 7.4$ & 0.515 \\
\hline $\mathrm{EF}[\%]$ & $64.9(58-71)$ & $63.8(50-72)$ & 0.055 \\
\hline \multicolumn{4}{|l|}{ Baseline laboratory data: } \\
\hline Creatinine [mg/dl] & $0.87 \pm 0.09$ & $0.87 \pm 0.1$ & 0.869 \\
\hline Glucose $[\mathrm{mg} / \mathrm{dl}]$ & $96.4(89-110)$ & $95(88-105)$ & 0.182 \\
\hline Total cholesterol [mg/dl] & $213(158-260)$ & $183(140-240)$ & 0.012 \\
\hline LDL cholesterol [mg/dl] & $85.9 \pm 17.9$ & $91.6 \pm 8$ & 0.083 \\
\hline HDL cholesterol [mg/dl] & $40.6 \pm 6.5$ & $43.1 \pm 6.6$ & 0.113 \\
\hline Triglyceride [mg/dl] & $139.8 \pm 43.3$ & $151.7 \pm 26.3$ & 0.161 \\
\hline $\mathrm{WBC}\left[\times 10^{3} / \mu \mathrm{l}\right]$ & $8 \pm 0.87$ & $7.7 \pm 0.9$ & 0.124 \\
\hline hs-CRP $\left[\times 10^{3} / \mu l\right]$ & $1.57 \pm 0.43$ & $0.53 \pm 0.23$ & $<0.001$ \\
\hline SUPAR [ng/ml] & $3.71(2.5-5.4)$ & $0.75(0.1-1.4)$ & $<0.001$ \\
\hline \multicolumn{4}{|l|}{ TIMI frame count: } \\
\hline LAD & $37.6(30-46)$ & $14(12-20)$ & $<0.001$ \\
\hline LCX & $35.2(28-41)$ & $14.3(10-21)$ & $<0.001$ \\
\hline RCA & $26.8(20-31)$ & $13.7(11-18)$ & $<0.001$ \\
\hline Mean & $33.3(30-38)$ & $13.9(12-17.3)$ & $<0.001$ \\
\hline
\end{tabular}

CSF - coronary slow flow, CAD - coronary artery disease, SBP - systolic blood pressure, DBP - diastolic blood pressure, EF - ejection fraction, $L D L$ - low-density lipoprotein, HDL - high-density lipoprotein, WBC - white blood cells, hs-CRP - high-sensitivity C-reactive protein, SUPAR - circulating soluble urokinase-type plasminogen activator receptor, TIMI - Thrombolysis in Myocardial Infarction, LAD - left anterior descending artery, $L C X$ - left circumflex artery, RCA - right coronary artery.

A

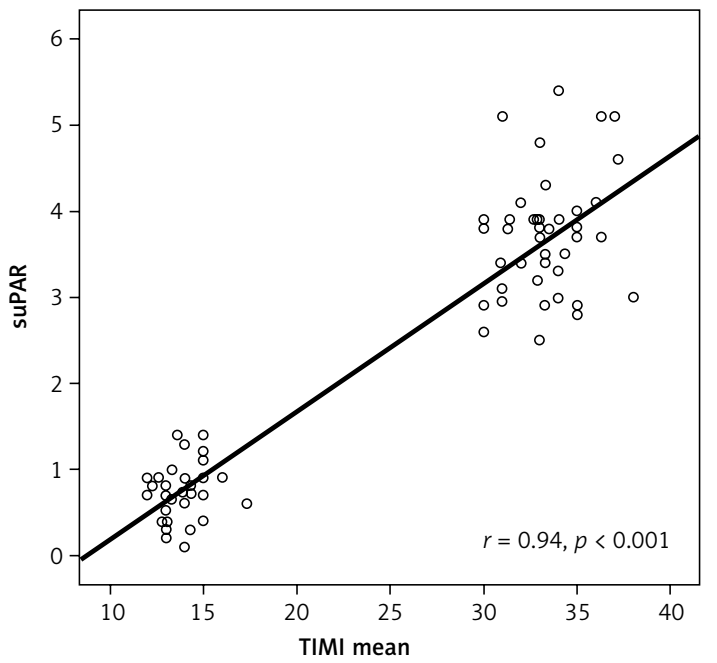

B

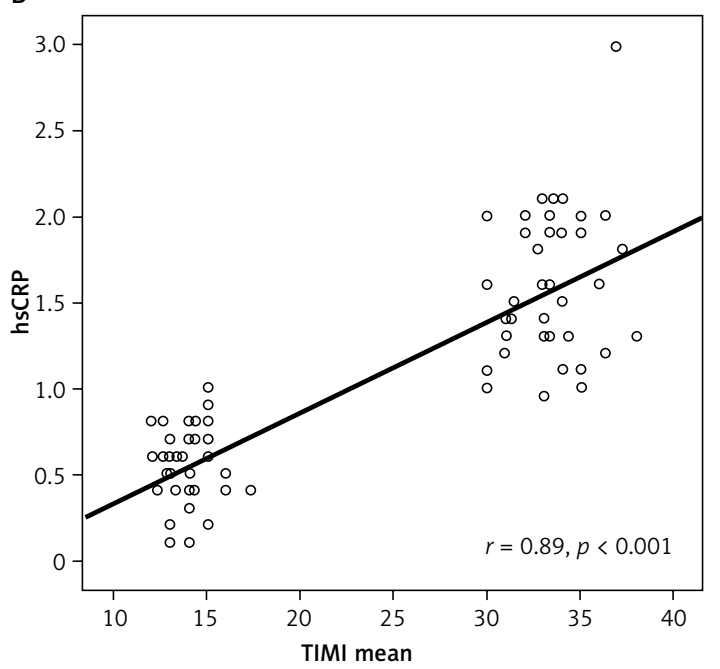

Figure 1. A - Serum suPAR levels were significantly higher among patients with SCF than controls. B - Serum hs-CRP levels were significantly higher among patients with SCF than controls 
found that plasma levels of inflammatory factors, hs-CRP and IL-6 in patients with SCF were significantly higher than those of control subjects [23]. Varol et al. found higher levels of neopterin, which is thought to be a marker of immune activation and macrophage activity, in the CSF group than the normal coronary flow group [24]. Selçuk et al. reported that serum concentrations of adiponectin, a modulator of the inflammatory response in the vascular wall, were decreased in patients with SCF and inversely correlated with mean TIMI frame count [25]. Durakoğlugil et al. reported significantly increased serum levels of sCD40, which is a proinflammatory agent, in patients with SCF [26]. Yıldırım et al. observed that levels of thrombin activatable fibrinolysis inhibitor (TAFI), also a proinflammatory factor, were higher in patients with SCF [27]. Aksan et al. reported that patients with CSF had elevated levels of neutrophil gelatinase-associated lipocalin (NGAL), which is released in response to active inflammation [28]. Çanga et al. found that increased levels of resistin, an inflammatory modulator, were associated with CSF [29]. Also, Çakmak et al. reported that visfatin, which is a novel adipokine and plays a role in inflammatory modulation, was associated with CSF [30].

Urokinase plasminogen activator (UPA) is a serine protease that, on binding its receptor, urokinase plasminogen activator receptor (UPAR), leads to the generation of plasmin [31]. UPA is produced by vascular endothelial cells, smooth muscle cells, monocytes, macrophages, fibroblasts and epithelial cells [32]. UPAR plays a role in development of atherosclerosis by orchestrating cellular adhesion, migration, and proliferation [31,33], and plasma sUPAR likely reflects cellular shedding of a section of UPAR from either inflammatory or endothelial cells. SUPAR is present in low concentrations in healthy individuals, where it has a role in neutrophil trafficking and stem cell mobilization [34]. Serum concentrations are elevated in infectious diseases induced by various pathogenic species [13, $35,36]$. sUPAR levels are also elevated in patients with inflammatory disorders, including arthritis [14] and inflammatory bowel disease [37]. On the basis of these data, suPAR has been considered a marker of (low-grade) activation of the immune system [38].

In the general population, individuals with high suPAR concentrations are at an increased risk for cardiovascular events, independent of Framingham risk factors $[39,40]$. Eapen et al. found that sUPAR level is an independent predictor of the presence and severity of coronary artery disease and of future adverse events [41]. In patients with non-ST elevation acute coronary syndrome, as well as in patients with ST-elevation myocardial infarction (MI), sUPAR predicts all-cause mortality and recurrent $\mathrm{MI}[18,19]$. suPAR was associated with subclinical organ damage independently of traditional risk factors [42]. One small study confirmed the relationship between the levels of sUPAR in plasma and carotid plaques and the presence of symptoms [43]. They concluded that plaque suPAR levels were associated with the vulnerable plaque phenotype. This, however, contradicted an earlier study suggesting that suPAR levels did not predict atherosclerotic plaque vulnerability [44]. The association between coronary microvascular dysfunction and inflammatory markers has been previously reported [45, 46]. Recently Mekonnen et al. found that plasma SUPAR level was an independent predictor of coronary microvascular function [47]. However, the relation between SCF and SUPAR levels has not been investigated previously. To the best of our knowledge, this is the first study investigating serum suPAR levels in patients with SCF and the relationship with TIMI frame count.

Some limitations of this study should be noted. The first is the small number of patients. Another limitation is that the analysis was based on a simple baseline determination that may not reflect the patient status over long periods.

In conclusion, we found that suPAR and hs-CRP levels were significantly elevated in patients with SCF compared with control subjects. This study shows that low-grade, chronic inflammation may be involved in the pathogenesis of SCF. Further prospective studies with a larger sample size are required to establish the pathophysiological and clinical significance of increased suPAR levels in patients with SCF.

\section{Conflict of interest}

The authors declare no conflict of interest.

\section{References}

1. Tambe AA, Demany MA, Zimmerman HA, Mascarenhas $E$. Angina pectoris and slow flow velocity of dye in coronary arteries - a new angiographic finding. Am Heart J 1972; 84: 66-71.

2. Kapoor A, Goel PK, Gupta S. Slow coronary flow: a cause for angina with ST segment elevation and normal coronary arteries. A case report. Int J Cardiol 1998; 67: 257-61.

3. Mangieri E, Macchiarelli G, Ciavolella M, et al. Slow coronary flow: clinical and histopathological features in patients with otherwise normal epicardial coronary arteries. Cathet Cardiovasc Diagn 1996; 37: 375-81.

4. Cin VG, Pekdemir H, Camsar A, et al. Diffuse intimal thickening of coronary arteries in slow coronary flow. Jpn Heart J 2003; 44: 907-19.

5. Sezgin AT, Sığırcı A, Barutçu I, et al. Vascular endothelial function in patients with slow coronary flow. Coron Artery Dis 2003; 14: 155-61.

6. Rıza Erbay A, Turhan H, Yaşar AS, et al. Elevated level of plasma homocysteine in patients with slow coronary flow. Int J Cardiol 2005; 102: 419-23. 
7. Kundi H, Gok M, Kiziltunc E, et al. The relationship between serum endocan levels with the presence of slow coronary flow: a cross-sectional study. Clin Appl Thromb Hemost 2015 Nov 25. pii: 1076029615618024.

8. Fragasso G, Chierchia SL, Arioli F, et al. Coronary slowflow causing transient myocardial hypoperfusion in patients with cardiac syndrome $X$ : long-term clinical and functional prognosis. Int J Cardiol 2009; 137: 137-44.

9. Thuno M, Macho B, Eugen-Olsen J. suPAR: the molecular crystal ball. Dis Markers 2009; 27: e157-72.

10. Donadello K, Scolletta S, Covajes C, Vincent JL. suPAR as a prognostic biomarker in sepsis. BMC Med 2012; 10: 2

11. Koch A, Voigt S, Kruschinski C, et al. Circulating soluble urokinase plasminogen activator receptor is stably elevated during the first week of treatment in the intensive care unit and predicts mortality in critically ill patients. Crit Care 2011; 15; R63.

12. Wittenhagen P, Kronborg G, Weis N, et al. The plasma level of soluble urokinase receptor is elevated in patients with Streptococcus pneumoniae bacteraemia and predicts mortality. Clin Microbiol Infect 2004; 10: e409-15.

13. Ostrowski SR, Ullum H, Goka BQ, et al. Plasma concentrations of soluble urokinase-type plasminogen activator receptor are increased in patients with malaria and are associated with a poor clinical or a fatal outcome. J Infect Dis 2005; 191: e1331-41.

14. Slot O, Brunner N, Locht H, Oxholm P, Stephens RW. Soluble urokinase plasminogen activator receptor in plasma of patients with inflammatory rheumatic disorders: increased concentrations in rheumatoid arthritis. Ann Rheumatic Dis 1999; 58: 488-92.

15. Chu SC, Yang SF, Lue KH, Hsieh YS, Hsiao TY, Lu KH. Urokinase-type plasminogen activator, receptor, and inhibitor correlating with gelatinase-B (MMP-9) contribute to inflammation in gouty arthritis of the knee. J Rheumato 2006; 33: 311-7.

16. Botha S, Fourie CM, Schutte R, Eugen-Olsen J, Pretorius $R$, Schutte AE. Soluble urokinase plasminogen activator receptor as a prognostic marker of all-cause and cardiovascular mortality in a black population. Int J Cardio 2015; 184: 631-6.

17. Kienast J, Padro T, Steins M, et al. Relation of urokinase-type plasminogen activator expression to presence and severity of atherosclerotic lesions in human coronary arteries. Thromb Haemost 1998; 79: 579-86.

18. Lyngbaek S, Andersson C, Marott JL, et al. Soluble urokinase plasminogen activator receptor for risk prediction in patients admitted with acute chest pain. Clin Chem 2013; 59: 1621-9.

19. Lyngbaek S, Marott JL, Moller DV, et al. Usefulness of soluble urokinase plasminogen activator receptor to predict repeat myocardial infarction and mortality in patients with ST-segment elevation myocardial infarction undergoing primary percutaneous intervention. Am J Cardiol 2012; 110: 1756-63.

20. Persson M, Ostling G, Smith G, et al. Soluble urokinase plasminogen activator receptor: a risk factor for carotid plaque, stroke, and coronary artery disease. Stroke 2014; 45: 18-23.

21. Cozen AE, Moriwaki H, Kremen M, et al. Macrophage-targeted overexpression of urokinase causes accelerated atherosclerosis, coronary artery occlusions, and premature death. Circulation 2004; 109: 2129-35.

22. Gibson CM, Cannon CP, Daley WL, et al. TIMI frame count: a quantitative method of assessing coronary artery flow. Circulation 1996; 93: 879-88.
23. Li JJ, Qin XW, Li ZC, et al. Increased plasma C-reactive protein and interleukin- 6 concentrations in patients with slow coronary flow. Clin Chim Acta 2007; 385: 43-7.

24. Varol E, Gülcan M, Aylak F, et al. Increased neopterin levels and its association with angiographic variables in patients with slow coronary flow: an observational study. Anadolu Kardiyol Derg 2011; 11: 692-7.

25. Selçuk H, Selçuk MT, Temizhan A, et al. Decreased plas ma concentrations of adiponectin in patients with slow coronary flow. Heart Vessels 2009; 24: 1-7.

26. Durakoğlugil ME, Kocaman SA, Çetin $M$, et al. Increased circulating soluble CD40 levels in patients with slow coronary flow phenomenon: an observational study. Anadolu Kardiyol Derg 2013; 13: 39-44.

27. Yildirim MN, Selcoki Y, Uysal S, et al. Thrombin activatable fibrinolysis inhibitor: its role in slow coronary flow. Herz 2014; 39: 993-1000.

28. Aksan G, Soylu K, Aksoy O, et al. The relationship between neutrophil gelatinase-associated lipocalin levels and the slow coronary flow phenomenon. Coron Artery Dis 2014; 25: 505-9.

29. Çanga A, Cetin M, Kocaman SA, et al. Increased serum resistin levels in patients with coronary slow-flow phenomenon. Herz 2013; 38: 773-8.

30. Çakmak HA, Aslan S, Yalcin AA, et al. Relationship between serum visfatin levels and coronary slow-flow phenomenon. Herz 2015; 40: 921-8.

31. Fuhrman B. The urokinase system in the pathogenesis of atherosclerosis. Atherosclerosis 2012; 222: 8-14.

32. Andreasen PA, Egelund R, Petersen HH. The plasminogen activation system in tumor growth, invasion, and metastasis. Cell Mol Life Sci 2000; 57: 25-40.

33. Waltz DA, Fujita RM, Yang X, et al. Nonproteolytic role for the urokinase receptor in cellular migration in vivo. Am J Respir Cell Mol Biol 2000; 22: 316-22.

34. Blasi F, Carmeliet P. UPAR: a versatile signalling orchestrator. Nat Rev Mol Cell Biol 2002; 3: 932-43.

35. Nebuloni M, Zawada L, Ferri A, et al. HIV-1 infected lymphoid organs upregulate expression and release of the cleaved form of UPAR that modulates chemotaxis and virus expression. PLoS One 2013; 8: e70606.

36. Rabna P, Andersen A, Wejse C, et al. Utility of the plasma level of suPAR in monitoring risk of mortality during TB treatment. PLoS One 2012; 7: e43933.

37. Lonnkvist $\mathrm{MH}$, Theodorsson $\mathrm{E}$, Holst $\mathrm{M}$, et al. Blood chemistry markers for evaluation of inflammatory activity in Crohn's disease during infliximab therapy. Scand J Gastroenterol 2011; 46: 420-7.

38. Backes Y, van der Sluijs KF, Mackie DP, et al. Usefulness of SUPAR as a biological marker in patients with systemic inflammation or infection: a systematic review. Intensive Care Med 2012; 38: 1418-28.

39. Lyngbaek S, Marott JL, Sehestedt T, et al. Cardiovascular risk prediction in the general population with use of sUPAR, CRP, and Framingham Risk Score. Int J Cardio 2013; 167: 2904-11.

40. Persson M, Engstrom G, Bjorkbacka H, et al. Soluble urokinase plasminogen activator receptor in plasma is associated with incidence of CVD. Results from the Malmo Diet and Cancer Study. Atherosclerosis 2012; 220: 502-5.

41. Eapen DJ, Manocha P, Ghasemzedah N, et al. Soluble urokinase plasminogen activator receptor level is an independent predictor of the presence and severity of coronary artery disease and of future adverse events. J Am Heart Assoc 2014; 3: e001118. 
42. Sehestedt T, Lyngbæk S, Eugen-Olsen J, et al. Soluble urokinase plasminogen activator receptor is associated with subclinical organ damage and cardiovascular events. Atherosclerosis 2011; 216: 237-43.

43. Edsfeldt A, Nitulescu M, Grufman H, et al. Soluble urokinase plasminogen activator receptor is associated with inflammation in the vulnerable human atherosclerotic plaque. Stroke 2012; 43: 3305-12.

44. Olson FJ, Thurison T, Ryndel M, Høyer-Hansen G, Fagerberg B. Soluble urokinase-type plasminogen activator receptor forms in plasma as markers of atherosclerotic plaque vulnerability. Clin Biochem 2010; 43: 124-30.

45. Tona F, Serra R, Di Ascenzo L, et al. Systemic inflammation is related to coronary microvascular dysfunction in obese patients without obstructive coronary disease. Nutr Metabol Cardiovasc Dis 2014; 24: 447-53.

46. Vaccarino V, Khan D, Votaw J, et al. Inflammation is related to coronary flow reserve detected by positron emission tomography in asymptomatic male twins. J Am Coll Cardiol 2011; 57: 1271-9.

47. Mekonnen G, Corban MT, Hung OY, et al. Plasma soluble urokinase-type plasminogen activator receptor level is independently associated with coronary microvascular function in patients with non-obstructive coronary artery disease. Atherosclerosis 2015; 239: 55-60. 